\title{
Revisiting Energy and Governmental Funds Allocation in Pakistan: A Novel Zero-Sum Gain DEA Approach
}

\author{
Nadeem Iqbal \\ Faculty of Management and Social Sciences \\ Ghazi University DG Khan, Pakistan \\ drnadeemiqbal1@gmail.com \\ Qaiser Abbas \\ Faculty of Management and Social Sciences \\ Ghazi University DG Khan, Pakistan \\ qabbas@gudgk.edu.pk \\ Mukhtiar Ali Erri \\ School of Business Administration \\ Shaheed Benazir Bhutto University, Shaheed Benazirabad \\ mukhtiarali@sbbusba.edu.pk \\ Dr. Shams ur Rehman \\ Assistant Professor, Northern University, Nowshehra \\ Shams.mashud@gmail.com
}

\begin{abstract}
Like many developing countries, Pakistan has limited energy production and governmental funding to support its development. This research focuses on energy efficiency levels and governmental funds distribution among four provinces in Pakistan. Based on balanced panel data from 2006 to 2016, this study develops a novel Zero-Sum Gain (ZSG) DEA approach to simultaneously assess energy efficiency levels and reallocate limited financial resources among provinces. Under the assumption of constant outputs, energy production and governmental funds are considered as input variables, while GDP and population as output variables. Results indicate that efficiency levels of Pakistan provinces range between 0.62 to 0.88 , thus suggesting room for improvement in funding allocation.
\end{abstract}

Keywords: Finance; energy; fund allocation; Zero-Sum Gain; DEA.

\section{Introduction}

Socio-economic development of nations not only rely on an adequate allocation of energy between economic agents but also on a proper distribution of governmental funds to support the increase of its production over the course of time (Buil, Catalán, and Martínez 2016). The globalization of world economy and countries dependence on energy has led to a progressively significant role for energy and availability of funds because these both are interrelated concepts. In fact, as regards energy production, the factor that plays highly important role is the availability of funds (Economics and York 2009).

In Pakistan, energy (electricity) is allocated among provinces based on their 
regional GDP and population which are also used as ratio criteria to split the total amount of federal tax revenues collected by the Pakistan government (NFC - National Finance Commission - funds). The funds distributed among provinces by the federal government are based upon NFC award criteria. Energy and NFC funds are considered as the cornerstones of economic development and social progress, consisting in one of the major drivers of Pakistan society (Iqbal and Akhtar 2015). It is worth noting that the poverty level in the country is very high (Ferré, Ferreira, and Lanjouw 2012) and the country nowadays is running on the loan from IMF (Tacneng 2015).

However, since the last year conducted national census, the provinces believe that their population today is much higher as compared to the figures currently used by the Pakistan government. Precisely, the provinces argue that they are getting less amount of money under NFC award criteria, yielding a conflict among the four provinces and federal government. Previous studies have highlighted that shortage of funds in the country is creating worse condition for energy production and supply in the country (Youssouf 2017). In fact, the funds distribution among provinces is going on according to the presidential order established five years ago based on the amount payable by the different departments of government including provincial governments.

Since Pakistan suffers from severe energy shortage due to insufficiency of funds literature suggests that provinces in the country are also playing a crucial role in worsening the debate of conflicted distribution of energy and funds for the future perspectives of the energy sector. Considering that, the Pakistan government has limited resources, the adoption of an alternative allocation approach that maximizes the utility of these limited resources - energy and funds - is deemed necessary. In fact, academic literature indicates shortage of funds and under-utilization of existing resources as major challenges to energy sector (Herrera Madueño et al. 2016), (Mohsin et al. 2018) and (Mohsin, Rasheed, and Saidur 2018).

Thus, in order to improve energy and NFC funds efficiency on a continuous basis, it is necessary to evaluate the efficiency of energy and NFC funds. This paper aims at contributing to fill this gap by providing formal models to quantify performance using Data Envelopment Analysis (DEA). However, the allocation of funds and energy quotas are a particular kind of efficiency problem where there is a fixed total amount to be distributed. This can be dealt with by the new Zero-Sum Gains DEA model, thus providing the basis for the introduction of policies and mechanisms that carry out more equitable, efficient energy and NFC funds allocation. This is necessary because different provinces in Pakistan usually have different resource endowments, industrial structures, economic development levels and energy consumption patterns that determine the provincial GDP, which cannot be apprehended by ordinary ratio criteria among provinces.

Therefore, this paper proposes the application of a novel Zero-Sum Gains DEA model for efficient allocation of energy and NFC funds among provinces based on Population and GDP, departing from the current approach where the Pakistan government uses ordinary ratio criteria. This paper not only presents an empirical estimation of energy and NFC funds allocation/relocation but also suggests policy 
guidelines to the Pakistan government based on key indicators. The paper is organized as follows. Section 2 presents the literature review. Section 3 focuses on the model and methodology. Section 4 applies the approach to allocate energy consumption target of different four provinces in Pakistan and analyses the differences between the primary allocation and the scheme with equity. Section 5 derives the conclusions and the policy implications of this study.

\section{Literature Review on Resource Allocation DEA Models}

The traditional DEA - Data Envelopment Analysis - CCR model (Charnes, Cooper, and Rhodes 1978) is one of the non-parametric cornerstone methods used for efficiency measurement. Based upon the traditional CCR model, many other DEA models have been proposed to determine the efficiency level of business units in different decision-making contexts, energy included. For example, the study of (Zhou and Ang 2008) summarized several linear programming models based on the DEA non-parametric approach, and measured the efficiency of energy use in free-market, opened economies. (Carley et al. 2012 and Iqbal et al. 2019). Significant decadal channel change 58-67years post-dam accounting for uncertainty in topographic change detection between contour maps and point cloud models. Geomorphology, Caballero, Y., Cheva et al. 2011) used a novel energy-technology efficiency index based on the DEA method, calculating the energy efficiency. The similar methodology has been used by various researchers in the field of energy economics and environment such as (Anser et al 2020, Asbahi et al 2019 and Mohsin et al 2020).

Resource allocation is a common issue tackled by efficiency measurement techniques. To reach the maximal utilization of limited resources many researchers have conducted studies on both theoretical and application aspects of resource allocation in different sectors analyzed the maximization of the overall efficiency across all DMUs - Decision Making Units - through the allocation of fixed resources. The authors introduced an alternative methodologies to yield unique solutions, grounded on the model and on additional constraints previously proposed in the study and assess the relationship between corporate social responsibility and earning management (Gras-Gil, Palacios Manzano, and Hernández Fernández 2016) and (Garcia-castro et al. 2014).

DEA resource allocation models can be categorized into three approaches. The first approach deals with efficiency-invariance, it consider efficiency of post-allocation and efficiency of pre-allocation for each DMU should be the same. But (Li et al. 2009) concluded that principle of allocation based efficiency invariance can be completely determined by the input side of DMUs, rather than outputs. The second approach deals with efficiency-maximization by allocating the resources on the base of maximizing post-allocation efficiencies for each DMUs. (Belu et al. 2013) introduced such a novel model but it requires several non-linear models improved by (Beasley 2003), while (Li et al. 2009) suggested that non-linear models proposed by linearized based by using common set of weights. The last approach is game based and this approach deals with game relation with DMUs. It can be apprehended as long as the less resources allocated to one DMU, the more resource is available to the other while the issue of game based DEA for each DMUs. They employed the cooperative game to resolve the issue of egoist's dilemma in order to 
resource allocation (Sun et al,2020 and Sun et al 2020).

In this regard the Zero-Sum Game is a situation when the gain or loss of one unit can balanced by the gain or loss of another unit though, DEA approach use the theory of Zero-Sum Game is called a Zero-Sum Game DEA. Zero-Sum-Gains DEA approach is equivalent to an undesirable outputs model. This is particularly useful here, as long as, in the "3E" namely economic, energy, and environmental research field. Additionally, (Gomes and Lins 2008) introduced a new a ZSG DEA model. This model consider the constant sum of inputs and outputs in resource allocation for sustainable economic development. However, in our study, we believe that the fair energy and NFC funds allocation mechanism can be derived from efficient competition across all DMUs, as long as over the course of time competition tends to improve the overall efficiency of all provinces. Therefore, in this research, the fixed proportion of energy and NFC funds for all provinces are (re) allocated by using a novel DEA model under a cooperative game approach.

\section{Methodology}

Fig. 1 depicts the framework observed to efficiently allocate energy and NFC funds among provinces. It represents the major steps followed in this study. In the first step, we used energy and NFC fund resources as allocated by the Pakistan government among provinces, observing their fair share ratios. Subsequently, we used the traditional DEA CCR model to measure the efficiency of that primary allocation. If the current allocation was found to be inefficient, these resources were reallocated using a cooperative game model to handle the current distributive conflict among large and small provinces of Pakistan. 


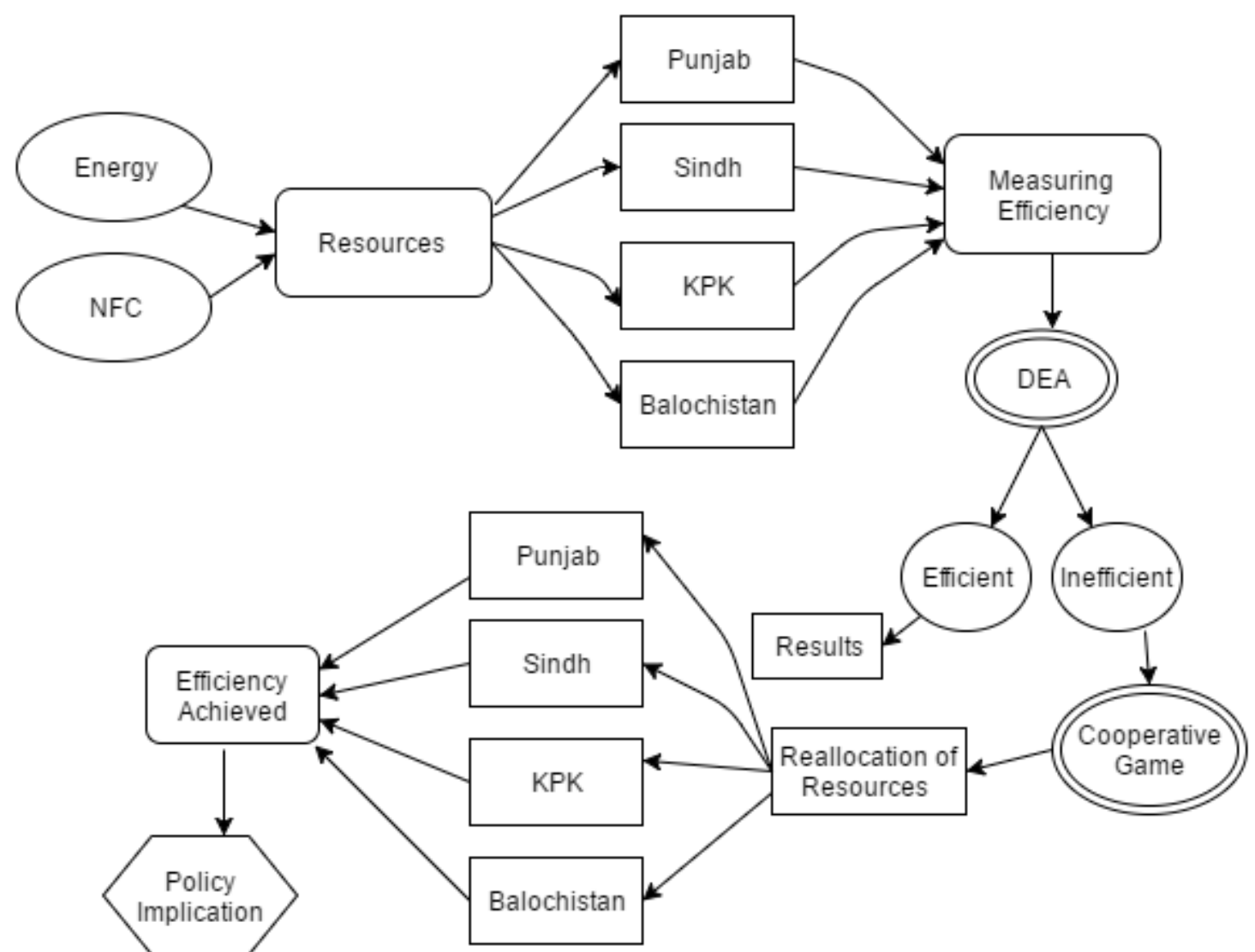

Fig. 1. Modeling steps for efficient allocation of energy and NFC Funds

Classically, the number of inputs-outputs and the choice of the DMUs seeks how the discrimination level exists between inefficient and efficient units in the given set of production (Seanna and Economics 2003). Two conflicting considerations occur during the evaluation of size of the data set. First consideration is about selection of DMUs because more DMUs ensure because a bigger size of population increase the probability of attaining high performance units among all DMUs which would measure the efficient frontier and perk up the discriminatory power. The second consideration is about selection of DMUs weights because large data set may decrease the homogeneity among the DMUs which means that some exogenous collision of no interest to the analyst. It may beyond the control of the manager which influence the results. Also, the computational necessities will yields an increase with larger data sets among the DMUs. But still there are few rules of thumb about the choice of inputs and outputs to choose their relation to the number of DMUs. The current study is consistent with (Sun et al,2020 and Sun et al 2020).

Traditional CCR-DEA model assumes that all input and output variables are completely independent. Besides, input and output variables do not influence on the size of each DMU. However, in some circumstances, this independent assumption does not hold for the total amount of a given variable. This being the case, if a given DMU attempts to increase the amount of its outputs, another DMU must decrease the outputs by the same amount, maintaining constant the total outputs of the system. 
Conversely, if a given DMU improves their efficiency by reducing inputs, another DMU should increase the inputs in order to sustain the total input level of the system (Miles 2007) and (Cho and Rhee 2015).

This being the case, the Zero-Sum-Gains DEA model can be modeled in two distinctive ways, considering the input-output alternative orientations. Model (2) is input oriented and $h_{r i}$ represents efficiency value for DMU, $h_{i}$ denotes the original efficiency value of DMU, $x_{i}$ and $y_{i}$ are used for the original inputs and output values, $\lambda_{\mathrm{j}}$ is the weight factor used in our model.

$$
\begin{aligned}
& E_{Z S G}=\min h_{r} \\
& h i_{r} Y_{r} \geq \sum_{j} \lambda_{j} y_{j}\left[1+\frac{Y_{r}\left(1-h I_{r}\right)}{\sum_{j \neq r} y_{j}}\right] \\
& \sum_{j} \lambda_{j} y_{j} \geq x_{j} \\
& \lambda_{j} \geq 0, \forall j
\end{aligned}
$$

The term $\mathrm{Y}_{\mathrm{r}}\left(1-\mathrm{hI}_{\mathrm{r}}\right) / \sum_{j \neq r} y_{j}$ assigns the extra-inputs of $\mathrm{DMU}_{\mathrm{j}}$ to other DMU. (Lins et al. 2003) proved the relationship between technical efficiency of the nonlinear programming $\mathrm{hI}_{\mathrm{r}}$ and technical efficiency of classic DEA $\mathrm{h}_{\mathrm{r}}$ as equation (2).

$$
h \boldsymbol{I}_{r}=h_{r}\left[1+\frac{\sum_{j \in W} Y_{j}\left(1-e_{j r} h k_{r}\right)}{\sum_{j \notin W} y_{j}}\right]
$$

Where the DMU whose technical efficiency from classic DEA model is not equal to 1, requires a hybrid modeling called ZSG DEA, where the term $e_{j r}=h_{j} / h_{i}$ is the technical efficiency ratio of classic DEA model having $D U_{j}$ and $D M U_{i}$. Also, in order to simplify the analysis process, the assumption constant returns to scale is adopted in this paper. It means an increase in the inputs will significantly cause a proportional increase in the outputs.

In this study, in order to efficiently allocate energy and NFC funds, we have taken GDP and population as output variables because these are the only criteria used by Pakistan government. Furthermore, energy and NFC funds were used as inputs in Zero-Sum-Gains DEA model. These inputs are the discretionary targets that needed to be controlled and allocated among provinces. To obtain a good discriminatory power out of the BCC and CCR models it is necessary that the numbers of DMUs should be the lower bound on the multiple of the number of inputs and the number of outputs (Mohsin et al 2018, Mohsin et al, 2019, Mohsin et al, 2020).

The conflicting considerations about selection of DMUs and about selection of DMUs weights because large data set may decrease the homogeneity among the DMUs. This reasoning is obtained from the flexibility issue in weight selection to allocate input and output values in obtaining the efficiency of each DMU Under such circumstances it may be possible that some indicators are ignored in obtaining of efficiency score. Since 
it is necessary for each entity in terms of its indicators to contribute in the overall efficiency score because all selected indicators should be taken as important and cannot be ignored. The main reason behind this restriction of weights flexibility is several practical considerations. Hatefi and Torabi argued that it is more realistic and convenient to let expert make consent on weights determination. Therefore, it is easy to drive the upper and lower bounds limit in practice. It yields a reasonable and realistic set of weights. It can be done to make a consensus among expert and decision makers for ensuring the relative importance of entity in terms of its sub-indicators.

Therefore, the energy and NFC funds quota allocation model can be expressed as equation (2):

$$
\begin{aligned}
& E_{Z S G}=\min \theta \\
& \sum_{j=1}^{m} \lambda_{j} X_{j} \geq X_{r} \\
& \sum_{j=1}^{m} \lambda_{j} Y_{j}\left[1+\frac{Y_{r}(1-\theta)}{\sum_{j=1, j \neq r}^{m} Y_{j}}\right] \leq \theta Y_{r}, \\
& \lambda_{j} \geq 0, j=1, \ldots m .
\end{aligned}
$$

Where $\theta$ is representing the Zero-Sum-Gains DEA efficiency measure whose total energy and NFC funds are controlled, $\mathrm{y}_{\mathrm{j}}, \mathrm{x}_{\mathrm{j}}, \mathrm{y}_{\mathrm{r}}$ and $\mathrm{x}_{\mathrm{r}}$ are input and output indicators, $\lambda_{j}$ is used as intensity variable, namely DMU efficiency frontier for "contribution" value. The Zero-Sum-Gains DEA efficiency $\mathrm{hr}_{\mathrm{i}}$ of each decision making unit (DMU) can be calculated using eq. (3). As depicted by Fig. 2, the lower technical efficiency of $\mathrm{DMU}_{\mathrm{F}}$ can be measured against the original DEA frontier. However, its efficiency improved to $\mathrm{F}^{\prime \prime}$ point by reducing the inputs level and the relatively high technical efficiency $D_{M} U_{G}$ moves to $G^{\prime \prime}$ point due to the investment in less efficient unit. After the reallocation of resources, all DMUs are in the Zero-Sum-Gains DEA frontier surface. 


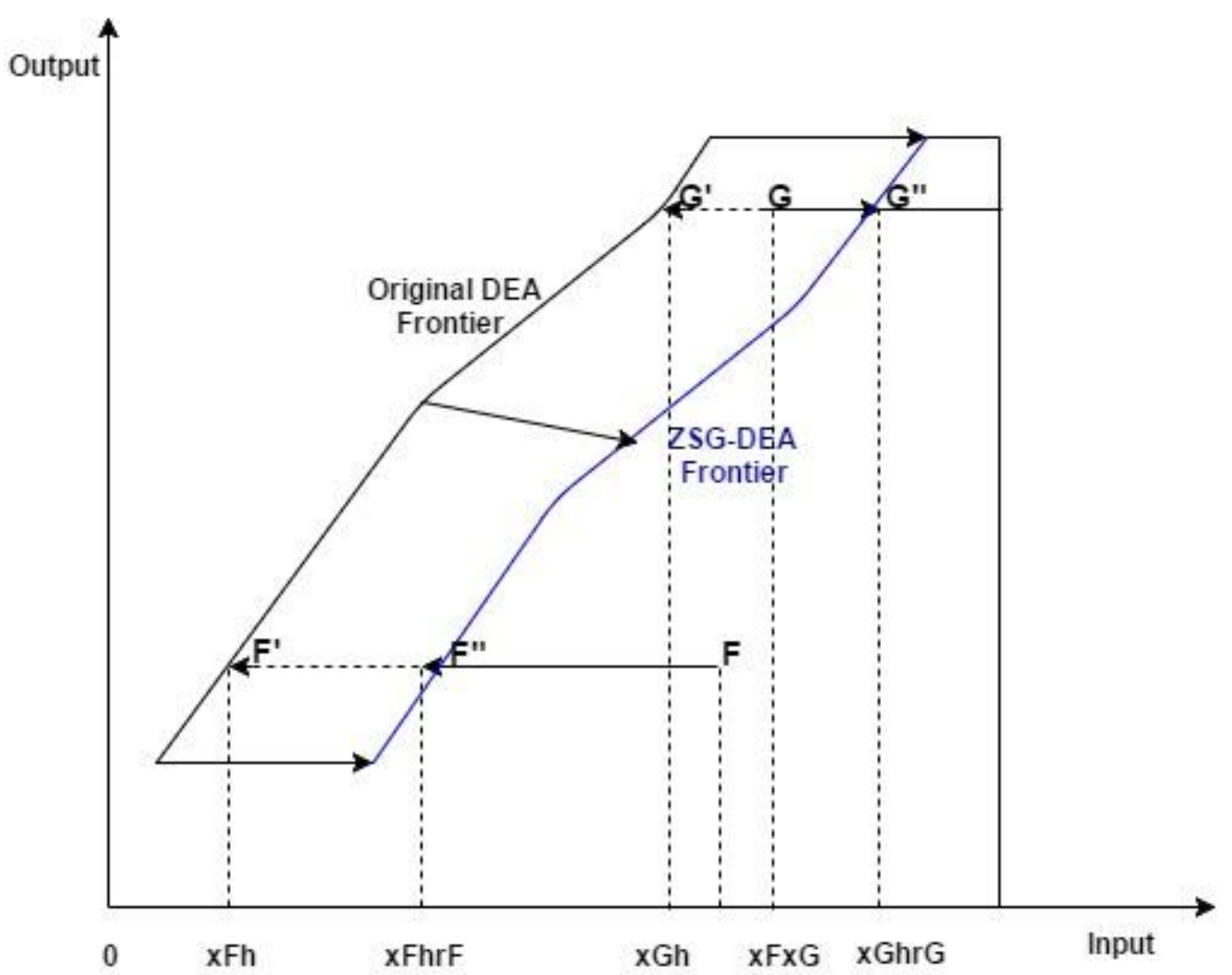

Fig. 2. The comparison of the frontier between the ZSG-DEA and original DEA The Zero-Sum-Gains DEA efficiency $\mathrm{hr}_{\mathrm{i}}$ of each decision making unit (DMU) can be calculated using eq. (3). As depicted by Fig. 2, the lower technical efficiency of $\mathrm{DMU}_{\mathrm{F}}$ can be measured against the original DEA frontier. However, its efficiency improved to $F^{\prime \prime}$ point by reducing the inputs level and the relatively high technical efficiency $D_{M} U_{G}$ moves to $G^{\prime \prime}$ point due to the investment in less efficient unit. After the reallocation of resources, all DMUs are in the Zero-Sum-Gains DEA frontier surface.

\section{Analysis and Discussion of Results}

Due to limitations of data, this study considers four provinces of Pakistan from 2006-2016. the autonomous regions has not been included in this study. On the edge of data of Pakistan's provinces from year 2006 to 2016, this study computed the CCR-DEA efficiency scores for the original energy and government funds allocation. These scores are presented in Table 1. Fig 3 depicts these scores in a bar-chart format. Result indicates that the average efficiency score of the provinces ranged in between 0.62 and 0.88 during these 11 years. It shows that energy and NFC-funds utilization is not efficient. Results for the ZSG-DEA are given in Table 2. As it can be seen, if we only consider efficiency for allocation of energy and NFC-funds among four provinces using the new proposed mechanism, the efficiency score for all provinces are going to become to 0.99 which is considered as all of the provinces are DEA effective and reach the production frontier. 


\begin{tabular}{|c|c|c|c|c|c|c|c|c|c|}
\hline \multicolumn{10}{|c|}{ Table 1. Efficiency Score } \\
\hline \multicolumn{3}{|c|}{ o.Bunjab } & \multicolumn{2}{|l|}{ Sindh } & \multicolumn{4}{|c|}{ Baluchistan } & KPK \\
\hline Yeab.8 & Ef & iency & Year & fficiency & Year & Efficiency & Year & & Efficienc \\
\hline 2006.7 & & 0.88 & 2006 & 0.65 & 2006 & 0.71 & 2006 & & 0.84 \\
\hline 28070.6 & & 0.87 & 2007 & 0.65 & 2007 & 0.71 & 2007 & & 0.83 \\
\hline 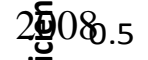 & & 0.88 & 2008 & 0.66 & 2008 & 0.71 & 2008 & & 0.84 \\
\hline 209.4 & & 0.88 & 2009 & 0.66 & 2009 & 0.71 & 2009 & & 0.82 \\
\hline 2010.3 & & 0.88 & 2010 & 0.66 & 2010 & 0.72 & 2010 & & 0.82 \\
\hline $201 \mathrm{~b} .2$ & & 0.88 & 2011 & 0.66 & 2011 & 0.71 & 2011 & & 0.82 \\
\hline 20120.1 & & 0.88 & 2012 & 0.68 & 2012 & 0.71 & 2012 & & 0.82 \\
\hline 20130 & & 0.87 & 2013 & 0.63 & 2013 & 0.73 & 2013 & & 0.84 \\
\hline 2014 & 2006 & 2884 & 2808142009 & 201.62 & 202914 & 20120.72013 & 28944 & 2015 & 2018.84 \\
\hline 2015 & & 0.85 & 2015 & 0.64 & $\underset{y e a r s}{2015}$ & 0.73 & 2015 & & 0.84 \\
\hline 2016 & & 0.84 & 2016 & 0.64 & $\begin{array}{r}\text { Years } \\
-\quad 2016 \\
\end{array}$ & 0.73 & 2016 & & 0.81 \\
\hline & & & Punjab & Sindh & Baluchist & KPK & & & \\
\hline
\end{tabular}

Fig. 3: The year-wise provincial efficiency of energy and NFC funds using original DEA model

Table 2. Reallocation and Efficiency of Energy and NFC Funds of Year 2016 Based Proposed Mechanism

\begin{tabular}{lllr}
\hline $\begin{array}{l}\text { Provinces } \\
\text { Efficiency }\end{array}$ & Energy & Funds \\
\hline Punjab & 51495.86 & 1146081 & 0.99 \\
Sindh & 28176.98 & 646684.5 & 0.99 \\
KPK & 13116.87 & 63227.61 & 0.99
\end{tabular}


After the reallocation, the different provinces acquire the various energy allocation quotas, which can be seen in table 2. There is only Sindh province whose energy and NFC funds quota increases after the reallocation. While Punjab, KPK and Baluchistan energy and NFC funds quota decreased. After reallocation of energy and fund using Zero-Sum-Gains DEA model the efficiencies are 0.99 of all the provinces. On the other hand the traditional CCR-DEA measures the on average efficiency of Punjab as highest with value 0.88 and Sindh efficiency has been measured as a lowest 0.62 , KPK and Baluchistan traditional CCR-DEA efficiency has been noted 0.84 and 0.71 respectively.

In accretion views, the total energy distribution amount and NFC funds amount of some provinces falls, especially the provinces whose initial efficiency was comparatively high, such as Punjab, Baluchistan and KPK while the amount of energy and NFC funds allocation of Sindh has been increased and its efficiencies increased by increasing its amount quota. Overall, the current state of the Zero-Sum-Gains DEA model, which increase the efficiency of all provinces occupied in the energy and NFC funds allocation, for those areas whose initial efficiency is higher, they will get more allocation of capital (NFC funds), but for the other regions, their allocation quota of NFC funds will be compressed. It can be said that in the allocation of a fixed amount of resources, the Zero-Sum-Gains DEA model will take care of those areas of high efficiency, and equally penalize the inefficient provinces.

Generally the overall conclusion states that the efficiency of the four DMUs, the provinces of Pakistan has been analyzed in the current study which is mixed with inefficient provinces. Consequently, there is a need to assign few reallocation model to upgrade the inefficient DMUs in order to make them efficient and to converge on the frontier of the best practices.

The results also shows that the scale is the main issue to assess the business format efficiency. Normally, the CRS score are less than the VRS, and all the CRS efficient DMUs are also VRS-efficient. Furthermore, managerial skills characterized by the BCC model scores are scarce. Finally, few DMUs features appear to increase the efficiency level. To clear explain the description of these findings, we conclude that as declared earlier, DEA does not classify the features which cause the inefficiency among all DMUs and it focus only on the DMUs, in this case the four provinces of Pakistan, in which inefficiency exists. Nevertheless, it consists of some suitable information due to the inputs and the outputs which give to this inefficiency. It may possible that the main cause for the pragmatic inefficiency is concurrent to asymmetric information in the four provinces of Pakistan.

\section{Conclusion and Policy Implications}

In this study, we assessed the Pakistan's resource (energy and funds) allocation among provincial regions. The motivation to assess the resource allocation was that (1) Pakistan is suffering from energy shortfall due inadequate planning and lack of support for resource saving target decomposition. (2) The budget of federal government of Pakistan is in deficit from more than two decades. To address the energy shortfall and shorten the budget deficit, first time this study proposed the 
application of Zero-Sum-Gains DEA model to characterize the efficiency level of energy and NFC funds among different provinces in Pakistan. Results from traditional efficiency of provinces have indicated that energy and NFC funds utilization is inefficient. However, to maximum utilize the energy and NFC funds we reallocated energy and NFC funds to improve overall efficiency score to get better results with undesirable outputs. Using CCR DEA model, we measured efficiency then we used the Zero-Sum-Gains DEA model that introduce the cooperative game to make DMUs compete with each other for a common weight set according to their current efficiency of energy and NFC funds allocation. Finally, present study stipulate that proposed mechanism of reduction and reallocation of energy and NFC funds is fair and equitable; it is beneficial for all provinces as efficiency score for all provinces reached optimal level in current scenario.

Furthermore, this study suggests policy guideline to address the current energy deficiencies and budget deficit. Based upon our findings federal government of Pakistan can design a short term and long term policy to efficiently utilize the limited resources. However, this efficient utilization can be helpful in reducing energy deficiency in the country and further it can also shorten the budget deficit. This paper uses the Zero-Sum-Gains DEA model which accumulates the properties of zero sum gain and DEA model based on the principle of efficiency. This proposed method has indicated that provinces with low initial efficiency score are Baluchistan and Sindh. Thus, our study suggested that federal government need to increase energy distribution and also increase the NFC funds in the budget to attain the optimal efficiency of all provinces in Pakistan. However, results from our study are much closer to the reality and easier to accept.

\section{References}

Anser, M.K., Mohsin, M., Abbas, Q., \& Chaudhry, I.S., (2020). Assessing the integration of solar power projects: SWOT-based AHP-F-TOPSIS case study of Turkey. Environmental Science and Pollution Research. https://doi.org/10.1007/s11356-020-09092-6.

Asbahi, A.A.M.H. Al, Gang, F.Z., Iqbal, W., Abass, Q., Mohsin, M., \& Iram, R., (2019). Novel approach of Principal Component Analysis method to assess the national energy performance via Energy Trilemma Index. Energy Reports 5, 704-713. https://doi.org/10.1016/j.egyr.2019.06.009

Beasley, J. E. (2003). Allocating Fixed Costs and Resources via Data Envelopment Analysis. European Journal of Operational Research 147(1): 198-216.

Belu, C. et al. (2013). Strategic Corporate Social Responsibility and Economic Performance. Applied Economics 45(19/21): 2751-64.

Buil, I., Sara, C., \& Eva, M. (2016). The Importance of Corporate Brand Identity in Business Management: An Application to the UK Banking Sector." $B R Q$ 
Business Research Quarterly 19(1): 3-12.

Carley, J. K., Pasternack, G. B., Wyrick, J. R., Barker, J. R., Bratovich, P. M., Massa, D. A., ... \& Johnson, T. R. (2012). Significant decadal channel change 58-67 years post-dam accounting for uncertainty in topographic change detection between contour maps and point cloud models. Geomorphology, 179, 71-88.

Charnes, A., W. W. Cooper, \& E. Rhodes. (1978). Measuring the Efficiency of Decision Making Units. European Journal of Operational Research 2(6): 429-44.

Cho, D., \& Dong, E. R. (2015). An Assessment of Inflation Targeting in a Quantitative Monetary Business Cycle Framework: Evidence from Four Early Adopters. Applied Economics 47(32): 3395-3413.

Ferré, C., Ferreira, F. H., \& Lanjouw, P. (2012). Is There a Metropolitan Bias? The relationship between poverty and city size in a selection of developing countries. The World Bank Economic Review, 26(3), 351-382.

Garcia-castro, Author, R., Miguel, A. A., Miguel, A. C., \& Miguel, A. A. (2014). Does Social Performance Really Lead Accounting to Financial for Endogeneity. Journal of Business Ethics 92(1): 107-26. http://dx.doi.org/10.1007/s10551-009-0143-8.

Gomes, E. G., \& M. P.E. L (2008). Modelling Undesirable Outputs with Zero Sum Gains Data Envelopment Analysis Models. Journal of the Operational Research Society 59(5): 616-23.

Gras-Gil, E., Mercedes, P. M., \& Joaquín, H. F. (2016). Investigating the Relationship between Corporate Social Responsibility and Earnings Management: Evidence from Spain.” BRQ Business Research Quarterly 19(4): 289-99.

Herrera Madueño, J., Manuel, L. J., Isabel, M. C., \& Domingo, M. M. (2016). Relationship between Corporate Social Responsibility and Competitive Performance in Spanish SMEs: Empirical Evidence from a Stakeholders' Perspective. BRQ Business Research Quarterly 19(1): 55-72.

Iqbal, N., \& Akhtar, M. R. (2015). Statistical Evaluation, Measuring and Managing Poverty In Rural Pakistan. Pak. J. Statist, 31(6), 709-716.

Iqbal, N., Tufail, M. S., Mohsin, M., \& Sandhu, M. A. (2019). Assessing Social and Financial Efficiency: The Evidence from Microfinance Institutions in Pakistan. Pakistan Journal of Social Sciences (PJSS), 39(1).

Li, Y., Feng, Y., Liang, L., \& Zhongsheng, H. (2009). Allocating the Fixed Cost as a 
Complement of Other Cost Inputs: A DEA Approach. European Journal of Operational Research 197(1): 389-401.

Lins, M., Estellita, P., Eliane, G., Gomes, J. Carlos, C.B. Soares de, M. Adelino José R. Soares de Mello. (2003). Olympic Ranking Based on a Zero Sum Gains DEA Model. European Journal of Operational Research 148(2): 312-22.

Miles, W. (2007). Do Inflation Targeting Handcuffs Restrain Leviathan? Hard Pegs vs. Inflation Targets for Fiscal Discipline in Emerging Markets. Applied Economics Letters 14(9): 647-51.

Muhammad Mohsin, Qaiser Abbas, Nadeem Iqbal, Robina Iram. Assessing Microfinance Institutions Efficiency by Radial and Non-radial DEA Approach. Pakistan journal of Social Science (PJSS). Volume 39, No 3, pp.803-816: 2019.

Mohsin, M., Abbas, Q., Zhang, J., Ikram, M., \& Iqbal, N. (2019). Integrated effect of energy consumption, economic development, and population growth on $\mathrm{CO} 2$ based environmental degradation: a case of transport sector. Environmental Science and Pollution Research, 26(32), 32824-32835.

Mohsin, M., Rasheed, A. K., \& Saidur, R. (2018). Economic viability and production capacity of wind generated renewable hydrogen. international journal of hydrogen energy, 43(5), 2621-2630.

Mohsin, M., Taghizadeh-Hesary, F., Panthamit, N., Anwar, S., Abbas, Q., \& Vo, X. V. (2020). Developing Low Carbon Finance Index: Evidence from Developed and Developing Economies. Finance Research Letters, 101520.

Mohsin, M., Rasheed, A. K., Sun, H., Zhang, J., Iram, R., Iqbal, N., \& Abbas, Q. (2019). Developing low carbon economies: An aggregated composite index based on carbon emissions. Sustainable Energy Technologies and Assessments, 35, 365-374.

Mohsin, M., Zhou, P., Iqbal, N., \& Shah, S. A. A. (2018). Assessing oil supply security of South Asia. Energy, 155, 438-447.

Seanna, D., \& The Economics. (2003). Abstracts of Award-Winning Theses. American Journal of Agricultural Economics 85(5): 1332-34. http://www.jstor.org/stable/1244917.

Sun, H., Mohsin, M., Alharthi, M., \& Abbas, Q. (2020). Measuring environmental sustainability performance of South Asia. Journal of Cleaner Production, 251, 119519.

Sun, H. P., Tariq, G., Haris, M., \& Mohsin, M. (2019). Evaluating the environmental 
effects of economic openness: Evidence from SAARC countries. Environmental Science and Pollution Research, 26(24), 24542-24551.

Sun, H., Pofoura, A. K., Mensah, I. A., Li, L., \& Mohsin, M. (2020). The role of environmental entrepreneurship for sustainable development: Evidence from 35 countries in sub-Saharan Africa. Science of The Total Environment, 140132.

Sun, L., Qin, L., Taghizadeh-Hesary, F., Zhang, J., Mohsin, M., \& Chaudhry, I. S. (2020). Analyzing carbon emission transfer network structure among provinces in China: new evidence from social network analysis. Environmental Science and Pollution Research, 1-20.

Tacneng, R. (2015). The Impact of Minority Foreign Ownership and Controlling Shareholder on Bank Risk and Performance: Evidence from an Emerging Economy. Managerial Finance 41(5): 526-46.

Youssouf, N. N. (2017). 4 Applied Economics and Finance Applied Economics and Finance. http://redfame.com/journal/index.php/aef/article/view/2540/2769.

Zhou, P., \& Ang, B. W. (2008). Linear Programming Models for Measuring Economy-Wide Energy Efficiency Performance. Energy Policy 36(8): 2901-6. 